\title{
Fabrication of Conductive Filaments for 3D-printing: Polymer Nanocomposites
}

\author{
Diogo José Horst ${ }^{1 * \mathbb{D}}$, Pedro Paulo de Andrade Junior ${ }^{1 \mathbb{C}}$, Charles Adriano Duvoisin ${ }^{2}{ }^{\mathbb{D}}$, Rogério de \\ Almeida Vieira ${ }^{2}$ (D) \\ 1 Federal University of Santa Catarina (UFSC), Department of Mechanical Engineering and Sciences, Dona Francisca 8300, \\ Zip Code: 89216-600, Joinville - SC, Brazil \\ 2 Federal University of São Paulo (UNIFESP), Department of Chemistry, Rua São Nicolau 210, Zip Code: 09913-030, \\ Diadema - SP, Brazil \\ * Correspondence: diogohorst@gmail.com;
}

Scopus Author ID 55823621400

Received: 14.04.2020; Revised: 10.05.2020; Accepted: 12.05.2020; Published: 17.05.2020

\begin{abstract}
With the promise of producing electrically conductive circuits, 3-dimensional-printing (3DP) filaments infused with carbon nanostructures are now commercially available; however, it is still difficult to control the mixture homogeneity between the polymer and conductive charge thereby increasing its conductive mobility. Herein, we describe the fabrication, characterization and application of conductive polymernanocomposites processed into filament form intended for 3DP of electronic circuits. For this, graphene, carbon nanotubes and carbon black fillers were loaded into several resin matrixes including ABS, PLA, HDPE, LLDPE, PETG, and PP. Electrical measurements, thermal, crystallographic and morphological profiles are here described. Filaments obtained present values of resistivity and conductivity ranging from 0.2 to $1.4 \mathrm{~S} / \mathrm{cm}$ and 0.71 to $5.0 \mathrm{~S} / \mathrm{cm}$ respectively. Thermal analysis showed that the processing temperature of materials studied is inside the standard range for extrusion and 3D-printing. Microscopic analysis revealed a heterogeneous mix between resins and fillers. The electrical and thermal stress test showed increases in resistivity and decreases in conductivity of prepared filaments since these quantities are inversely proportional.
\end{abstract}

Keywords: Conductive filaments; carbon nanostructures; electronic circuits; fillers; fused deposition modeling; 3D-printing materials.

(C) 2020 by the authors. This article is an open access article distributed under the terms and conditions of the Creative Commons Attribution (CC BY) license (https://creativecommons.org/licenses/by/4.0/).

\section{Introduction}

3DP is a unique technology that potentially offers a high degree of freedom for the customization of practical products that incorporate electrical components. To date, 3D printable conductive filaments with sufficiently high conductivities to fabricate practical circuits remain lacking for fused deposition modeling [1,2].

As 3DP technology has expanded, the need for multilaterals that support molten deposition modeling and other forms of additive manufacturing (AM) is increasing [3]. The employment of 3DP for the fabrication of advanced multi-functional composites is attracting increased interest of the research community due to the opportunities offered by this technology [4].

Carbon materials, due to their good chemical stability and versatile nanostructure, have been widely used in 3DP for different applications [5]. 
Several studies have been reported on Desktop 3DP of polymernanocomposites (PNCs) acid (PLA) and acrylonitrile butadiene styrene (ABS) $[6,7,8,9,10,11]$ however the development of new conductive PNC materials for a desktop 3D printer are highly desirable to achieve better printability, mechanical properties and electrical conductivity [12].

Desktop 3DP of PNCs with conductive nanofillers such as carbon nanotubes (CNTs) graphene and carbon black allows building objects with multifunctional properties having good electrical and thermal conductivity, mechanical strength and stiffness at relatively low cost [13].

Fused depositing modeling (FDM) is a fast, efficient process among 3DP techniques allowing the fabrication of highly conductive graphene flexible circuits by 3DP [14] however it is still limited by the availability of application specific functional materials [12].

Even if the conductivity of materials is still a challenge, due to the blending of conductive materials in a polymer matrix, typically made of dielectric materials, very recently a wide variety of composite materials have become available, with interesting conductive properties [19,20]. Unfortunately, these composites are often critical for 3DP due to their thermal expansion coefficient, glass transition temperature, and mechanical properties $[21,22,23,24,25]$.

Here we show the fabrication of electrically conductive filaments intended for the 3Dprinting of electronic circuits using several polymer matrix charged with the carbon nanostructures: graphene, carbon nanotubes and carbon black. The electrical, thermal and morphological characteristics of the materials obtained are described.

\section{Materials and Methods}

\subsection{Materials.}

Graphene (GR) thin nanoplates (catalog XFQ021), single-walled carbon nanotubes (CNT's) (catalog XFS08) and conductive carbon black (CB) (catalog XFI15) with particle size between 2-10 $\mathrm{nm}$ diameter and 10-30 $\mu \mathrm{m}$ length, and conductivity between $500-1100 \mathrm{~S} / \mathrm{cm} 2$ were purchased from XFnano, China. The thermoplastic resins: polylatic acid (PLA), acrylonitrile butadiene styrene (ABS), polypropylene (PP), high density polyetylene (PEADHDPE), linear low density polyethylene (PEBDL-LLDPE) and glycol modified polyethylene terephthalate (PETG) in pellet form were purshased from Brasken, Brazil.

\subsection{Preparation of polymer nanocomposites.}

Conductive filaments were prepared by hot mix blending the resins with the carbon nanostructures $15 \%$ w.t being added into a hot melt desktop single screw extruder (Filastruder, GA, USA). The extrusion was performed at $140-200{ }^{\circ} \mathrm{C}$, the rotor screw was set at $40-50 \%$ of maximum speed with speed maintained at $20 \mathrm{rpm}$, thereby forming printable nanocomposites filaments measuring $1.75 \mathrm{~mm}$ diameter cooled and then rolled into $1 \mathrm{~kg}$ coils. For 3DP of circuits, the architecture was primarily designed in CAD (Autocad 2004) and files exported to STL, and digitally loaded into Makerware. Once objects were rendered in Makerware, the software converts imported digital objects into a series of G-codes that instruct the printer to print the desired geometry layer-by-layer as needed. Electronic circuits were 3D-printed using a Fused Deposition Modelling (FDM) machine (Prusa Mendel-I3, USA) with printing temperature maintained at $180-240{ }^{\circ} \mathrm{C}$ and table heating at $60^{\circ} \mathrm{C}$; the feeding speed was 
maintained at $10 \mathrm{~mm} / \mathrm{min}$; and the output measure of the hot end was $0.4 \mathrm{~mm}$ with resolution between 0.1-0.3 mm.

\subsection{Electrical measurements.}

In resistance and conductivity measurements, silver paint (Electron Microscopy Sciences, catalog number: 12630) was applied in small areas (width: 1-2 mm; length: 3-4 mm). Samples generally reduce the contact resistance between the measuring probes and the conductive thermoplastic composite, being dried at room temperature for at least 12 hours before measuring their electrical resistance. Some areas of the conductive thermoplastic were subsequently connected to a Keithley source (Model6430). The electrical resistance of the samples was measured using four and two point methods under an applied voltage of $1 \mathrm{~V}$, the electrical conductivity was measured using portable conductivity meter (Akso). The test procedures were adapted from [1].

In electrical stress test, prior to the stress test, the strength of 3D-printed plastic filaments was measured with the Keithley font (Model6430) and recorded. Printed filaments were subsequently connected in parallel within a plastic box to insulate user wiring. Two electrical cables were connected to a power source (AC), with voltage set to 12 VRMS (mean square value). After seven days, the printed wires were removed from the box and its resistance measured and recorded.

\subsection{Scanning Electron Microscopy (SEM).}

In SEM, conductive filaments measuring $1 \times 1 \mathrm{~cm}$ were used as test specimens being inserted in specific stubs and covered with a thin gold layer by sputtering using 10-8 vacuum chamber and then placed in the sample holder of JEOL JSM-6701F equipment.

\subsection{X-ray Diffraction $(X R D)$.}

In XRD, carbon nanostructures in powder form were used, this characterization was performed is a PANalytical Empyrean analytical equipment using copper target $(\mathrm{CuK} \alpha$ $1.5418 \AA$ radiation), $2 \theta$ from $5^{\circ}$ to $70^{\circ}$, with sweep speed of $0.05^{\circ} / \mathrm{s}$, voltage of $40 \mathrm{kV}$ and 40 $\mathrm{mA}$ current.

\subsection{Differential Scanning Calorimetry (DSC).}

In DSC, samples were weighed $(3.0 \pm 0.5 \mathrm{mg})$ and hermetically sealed in aluminum crucibles being placed in a Shimadzu calorimeter model DSC-60 under an atmosphere of nitrogen, flow $50 \mathrm{ml} \mathrm{min}-1$; the heating ratio was maintained from $20^{\circ} \mathrm{C} \mathrm{min}-1$ to $550{ }^{\circ} \mathrm{C}$. The heating rate was maintained at $10^{\circ} / \mathrm{min}$ with nitrogen flow of $100 \mathrm{~mL} / \mathrm{min}$. The equipment was calibrated for temperature with indium standard $\left(156.6 \pm 0.3{ }^{\circ} \mathrm{C}\right)$ through their melting peak. The enthalpy and heat flow were calibrated using the heat of fusion of indium $(28.59 \mathrm{~J} / \mathrm{g} \pm$ 0.30 ) using the same conditions as the samples.

\subsection{Thermal stress test.}

A digital heating plate (Ika RCT Basic Hotplate) was used, the surface of the heating plate was covered with electrical tape to insulate the electrically conductive wires from the metal surface of the heating plate. For each component, five printed yarns were fixed uniformly 
to the hot plate with thin strips of tape near the two ends of each filament (about 3-4 mm from the two ends of each printed yarn). The silver ink was applied to both ends of each printed filament to minimize contact resistance during electrical measurement. The thermal test started as soon as the paint dries. The printed wires were heated and cooled to the desired temperature set on the heating plate. The heating plate temperature was verified using a portable digital thermocouple (Fluke 52 II thermometer). Due to the continuous fluctuation of the surface temperature of the plate, the samples were equilibrated for at least $10 \mathrm{~min}$ until the heater reaches the set temperature and its electrical resistance was measured using a Keithley measuring unit (Model 6430).

\section{Results and Discussion}

\subsection{Preparation of polymer nanocomposites.}

The Figure 1 shows the equipments used in the manufacture and printing of conductive filaments $(1.75 \mathrm{~mm})$ as well as simple 3D-printed circuits. The Table 1 shown in sequence presents the recommended (ideal) temperatures for the extrusion and printing of samples.

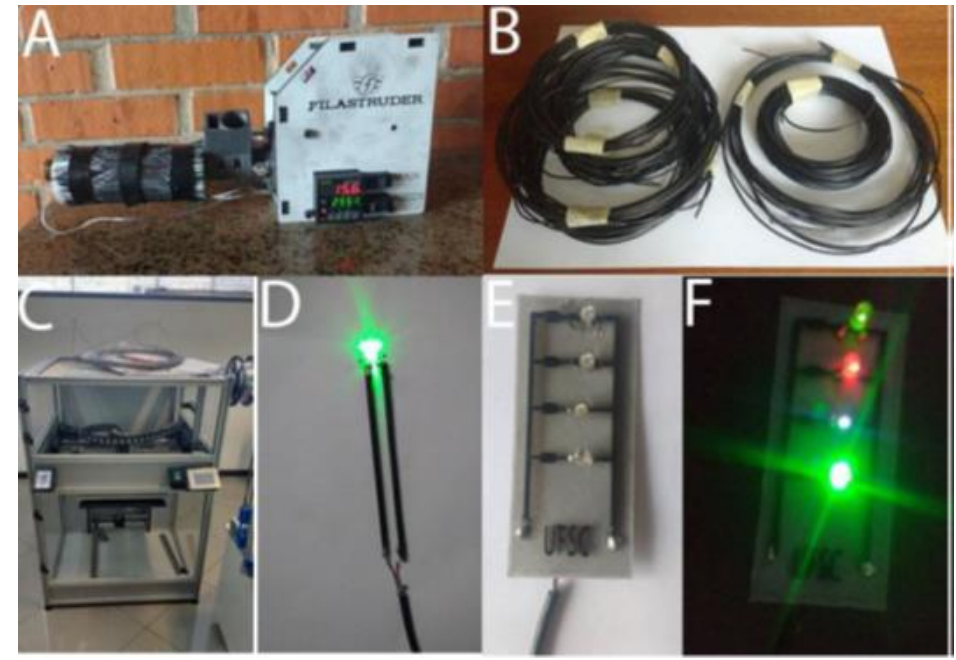

Figure 1. Experimental works: a) extruder machine; b) eletrical conductive filaments obtained; c) 3DP machine; d) simple circuit with one led lamp; e) 3D printed circuit without charging; and f) $5 \mathrm{~V} \mathrm{C} / \mathrm{C}$ charged circuit with four led lamps.

\subsection{Electrical measurements.}

The Figure 2 shows the mean values of five measurements of the electric resistivity and conductivity of filaments obtained when exposed to $10 \mathrm{~V} \mathrm{C/C}$.

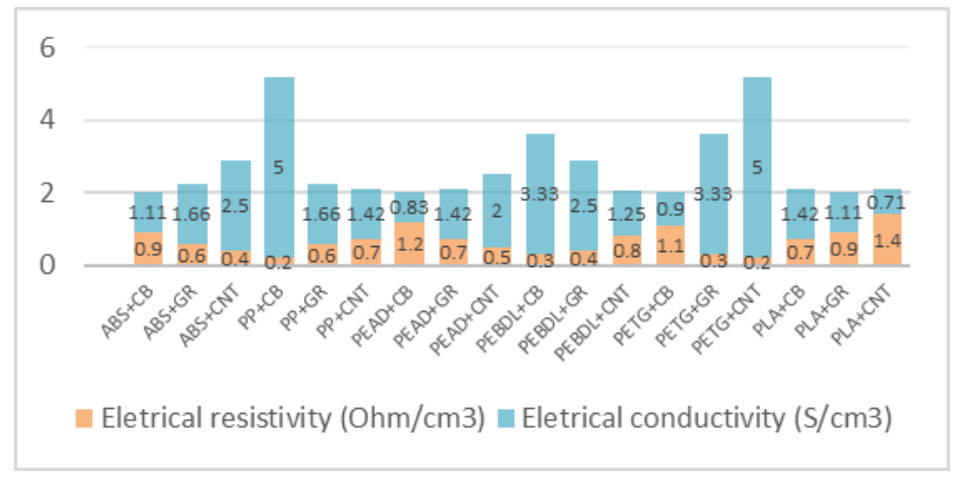

Figure 2. Electrical resistivity and conductivity of 3DP filaments. 
Figure 3 and Figure 4 show the mean values of five measurements of the electric resistivity and conductivity of filaments.

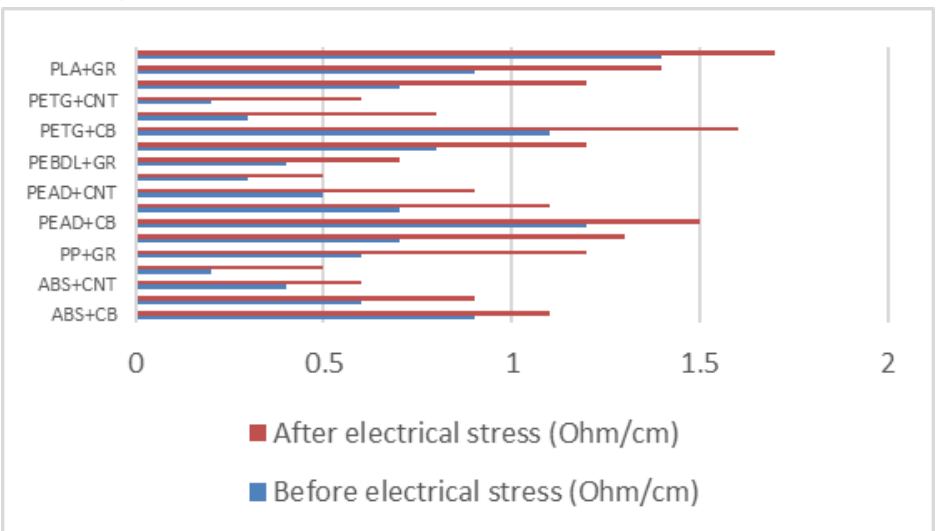

Figure 3. Electrical resistivity before and after the electrical stress test.

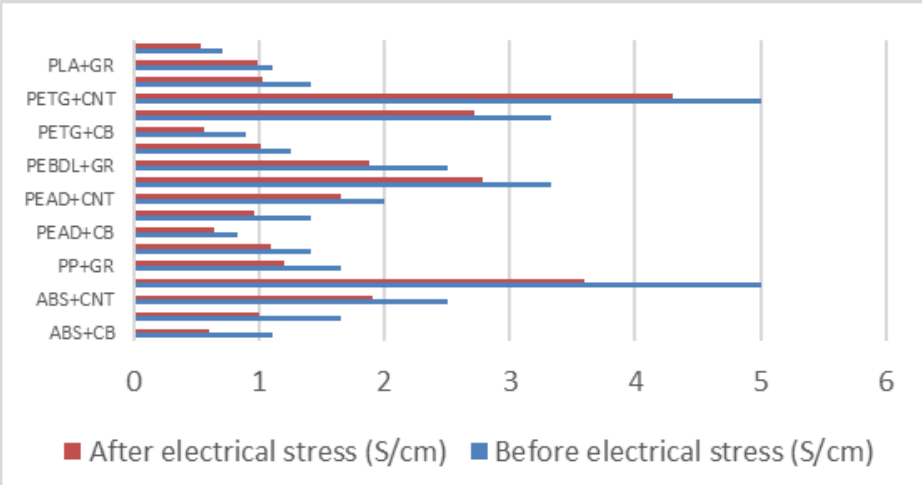

Figure 4. Electrical conductivity before and after the electrical stress test.

\subsection{SEM analysis.}

Figure 5 shows SEM images of the cross section fracture and surface morphology of filaments with magnification of 350x and 1500x:

Table 1. Ideal temperature for the extrusion and printing of samples.

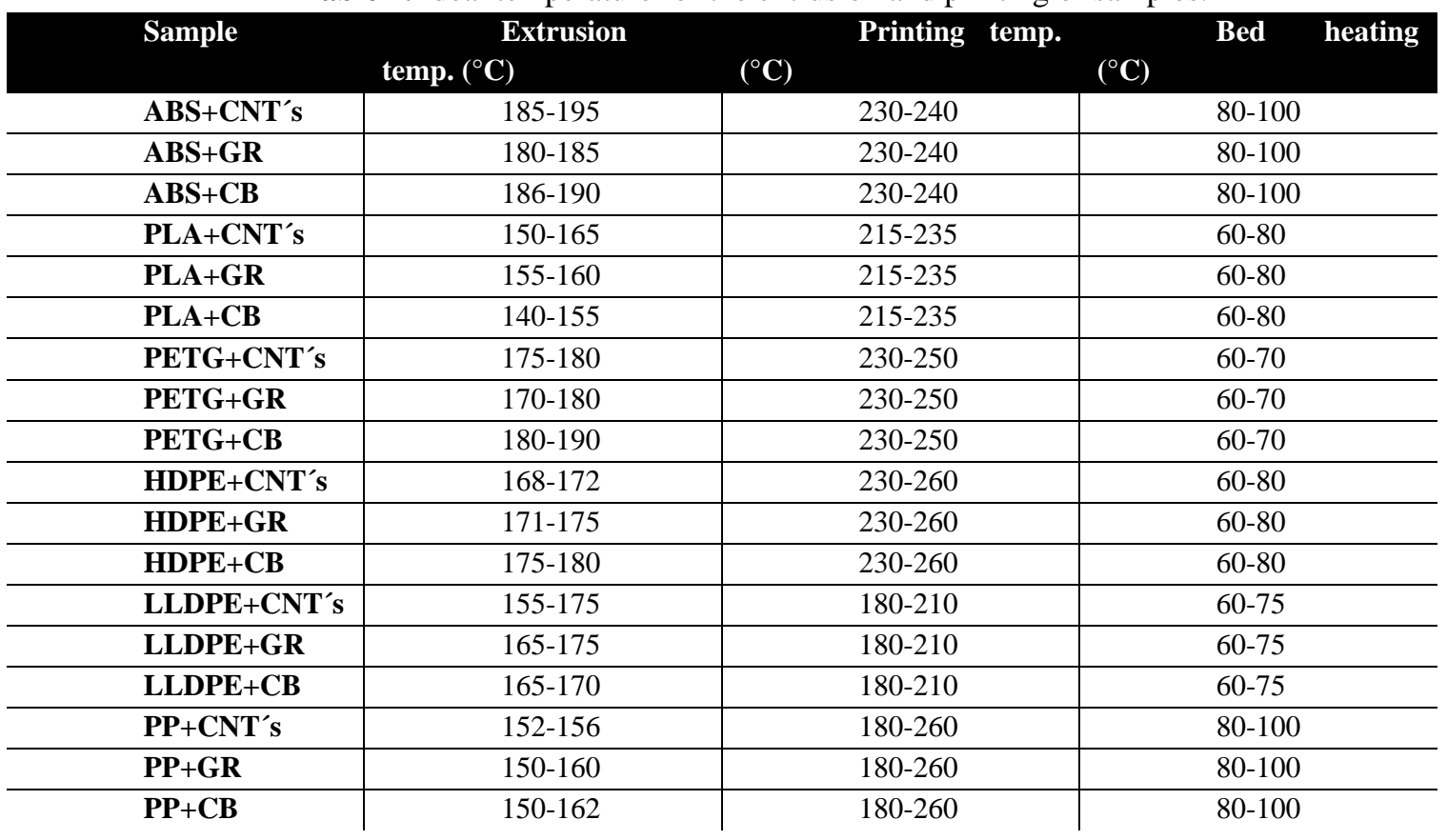




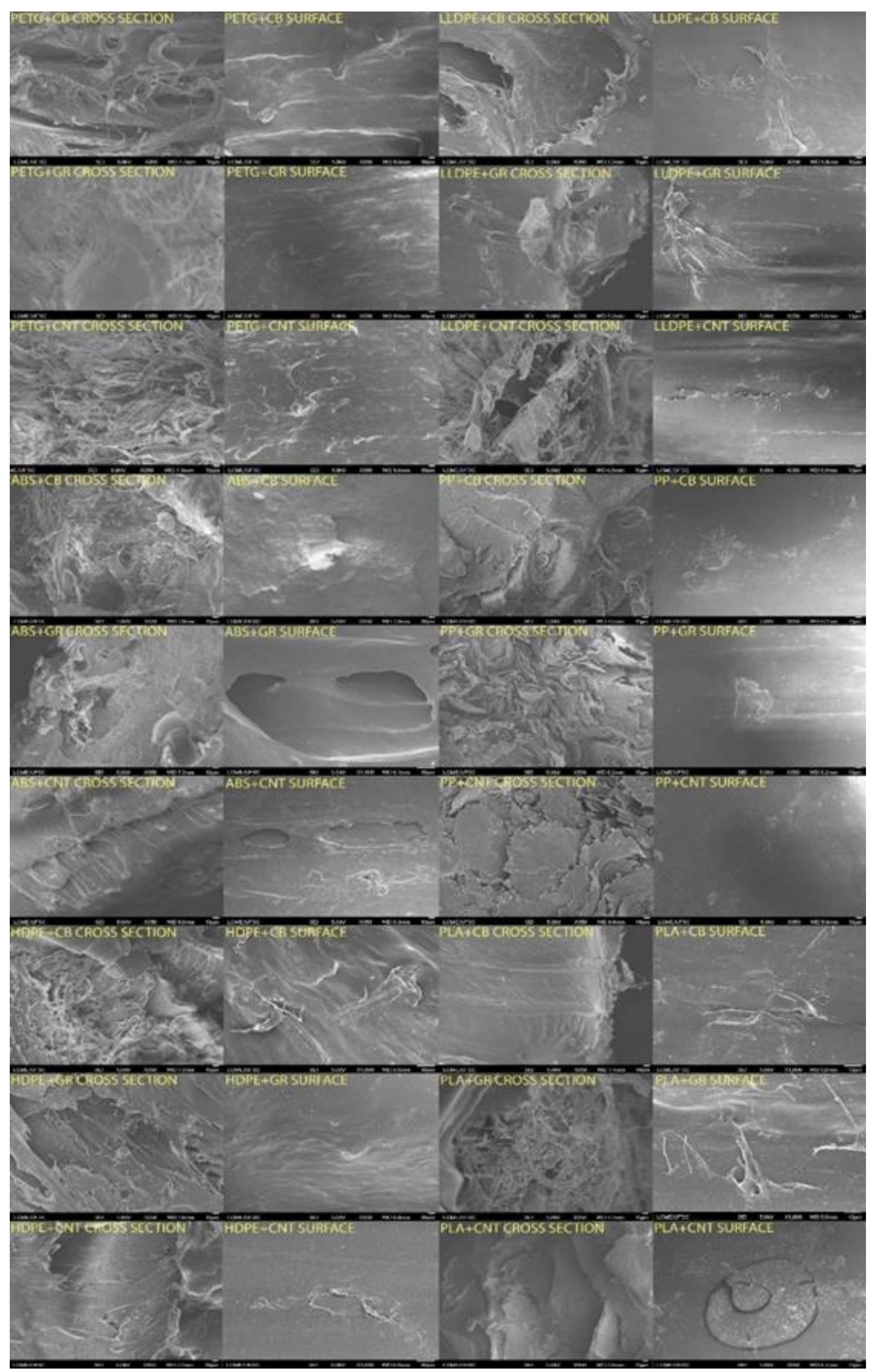

Figure 5. SEM images showing the cross section fracture and surface morphology of filaments with magnification of $350 \mathrm{x}$ and $1500 \mathrm{x}$. 
As can be seen, with $15 \%$ loading, there was a heterogeneous mixture between the carbon nanostructures and the polymeric matrixes, in few cases presenting accumulations of GR, CNT's or CB grains in specific spots. In some cases material surface failures such as holes and cracks have occurred, mainly due to the resolution (accuracy) and abrasiom of the printer nozzle $(0.4 \mathrm{~mm})$.

\subsection{XRD analysis.}

Figure 6 shows the XRD spectrum of carbon nanostructures in powder form. Typical peaks of graphene were observed at $2 \theta$ of $\sim 26^{\circ}$ and $\sim 43^{\circ}$, respectively, which could be indexed to the characteristic peak reflections of graphite from the graphene (JCPDS No. 01-0646) [16]. The peak at 26.061o is attributed to the characteristic peak of CNTs in powder form (JCPDS, Card No. 75- 1621) [17]. The peak observed around $26^{\circ}$ is due the appearance of cubic carbon (carbon black) (JCPDS card, No. 00-060-0053) [18].

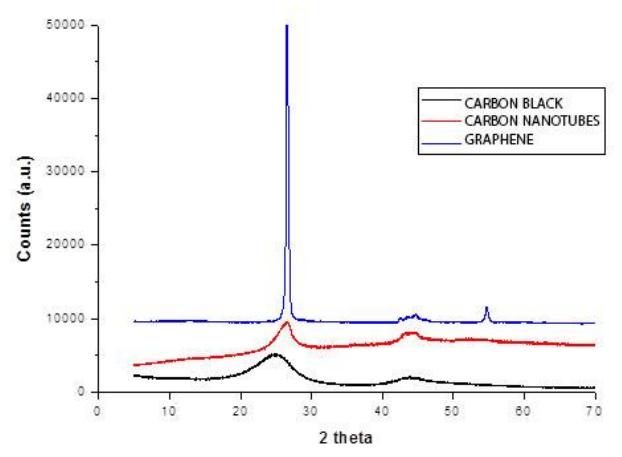

Figure 6. XRD spectrum of carbon nanostructures in powder form.

\subsection{DSC analysis.}

The Figure 7 shows samples DSC thermograms.
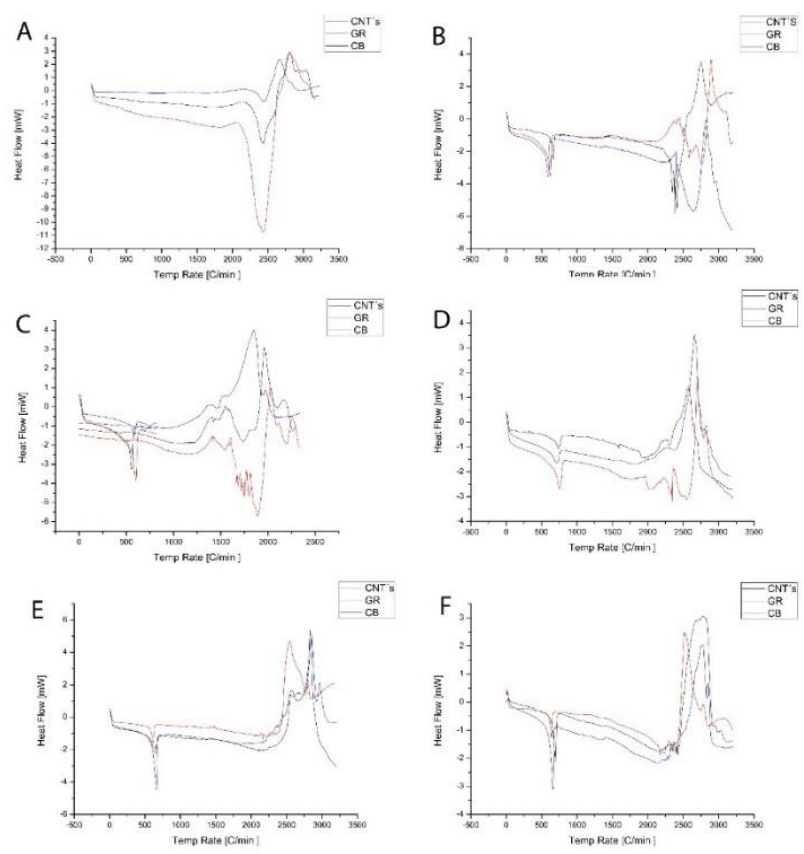

Figure 7. DSC thermogram of samples. Legend: A) ABS; B) PEAD-HDPE; C) PEBDL-LLDPE; D) PETG; E) PLA; F) PP. 
In sample A, the initial weight loss represents the glass transtition (Tg) around 180-195 ${ }^{\circ} \mathrm{C}$; sample B Tg occurs from $168-180{ }^{\circ} \mathrm{C}$; sample $\mathrm{C}$ Tg occurs around $155-175{ }^{\circ} \mathrm{C}$; sample D $\mathrm{Tg}$ occurs around $170-190{ }^{\circ} \mathrm{C}$; sample E Tg occurs from $140-165^{\circ} \mathrm{C}$; and sample $\mathrm{F}$ Tg occurs from $150-165{ }^{\circ} \mathrm{C}$. Noteworthy, around $500{ }^{\circ} \mathrm{C}$ all the resins studied presents changes from rubbery to viscous flow reaching its melting temperature (Tm) at around $2000{ }^{\circ} \mathrm{C}$. Its $\mathrm{Tg}$ from glassy state to rubbery state remains inside the ideal temperature for extrusion and 3D-printing without compromising the inherent characteristics of the polymers. The addition of different fillers in the proportion studied did not present significant changes in the thermal stability of materials in most cases remaining inside the standard processing temperature for extrusion and 3D-printing $[19,20]$.

\subsection{Thermal stress.}

Figure 8 and Figure 9 show the electrical resistivity and conductivity of filaments obtained before and after the thermal stress test, respectively. A slight increase in resistivity resulting in a drop in conductivity was noted, considering that the two measured quantities are inversely proportional.

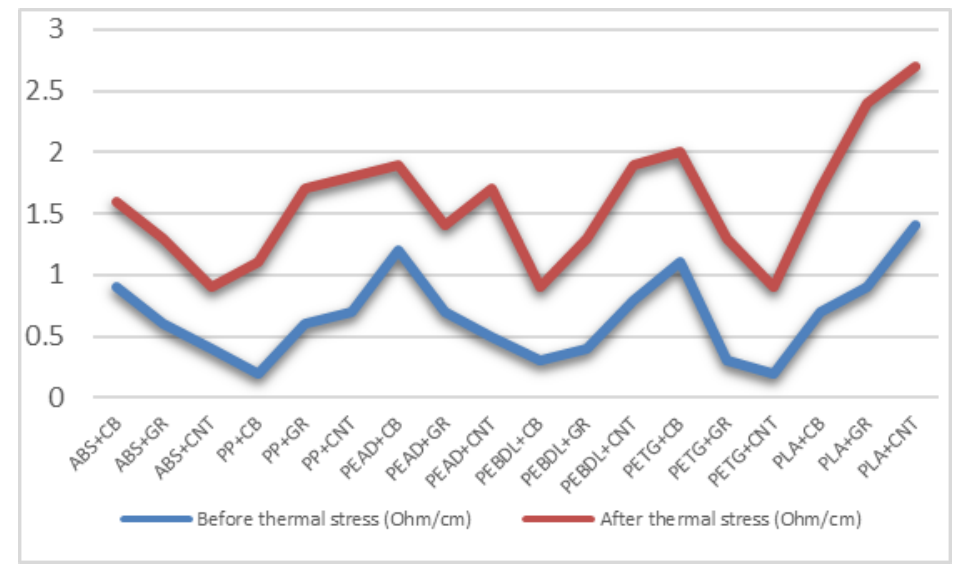

Figure 8. Electrical resistivity before and after the thermal stress test.

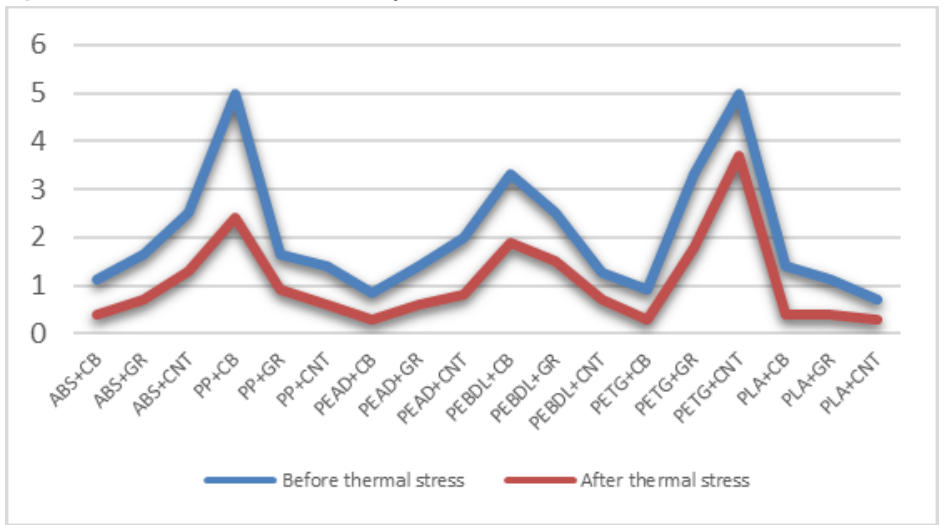

Figure 9. Electrical conductivity before and after the thermal stress test.

\section{Conclusions}

Conductive filaments obtained present values of resistivity and conductivity ranging from 0.2 to $1.4 \mathrm{~S} / \mathrm{cm}$ and 0.71 to $5.0 \mathrm{~S} / \mathrm{cm}$, respectively. Thermal analysis showed that the processing temperature of materials is inside the standard range for extrusion and 3D-printing. Microscopic analysis revealed a heterogeneous mix between resins and carbon nanostructures. The electrical and thermal stress test showed increases in resistivity and decreases in conductivity of filaments since these quantities are inversely proportional. 


\title{
Funding
}

This study was financed by CAPES, Brazil [Financial Code 001].

\section{Acknowledgments}

\begin{abstract}
The authors would like to thank the LCME-UFSC for technical support in SEM work and also the Technological Institute of Aeronautics (ITA) for supporting XRD work.
\end{abstract}

\section{Conflicts of Interest}

The authors declare no conflict of interest.

\section{References}

1. Kwok, S.W.; Goh, K.H.H.; Tan, Z.D.; Tan, S.T.M.; Tjiu, W.W.; Soh, J.Y.; Ng, Z.J.G.; Chan, Y.Z.; Hui, H.K.; Goh, K.E.J. Electrically conductive filament for 3D-printed circuits and sensors. Applied Materials Today 2017, 9, 167-175, https://doi.org/10.1016/j.apmt.2017.07.001.

2. Diogo José, H.; Pedro Paulo Andrade, J. 3D-Printed Conductive Filaments Based on Carbon Nanostructures Embedded in a Polymer Matrix: A Review. International Journal of Applied Nanotechnology Research (IJANR) 2019, 4, 26-40, https://doi.org/10.4018/IJANR.2019010103.

3. Dilberoglu, U.M.; Gharehpapagh, B.; Yaman, U.; Dolen, M. The Role of Additive Manufacturing in the Era of Industry 4.0. Procedia Manufacturing 2017, 11, 545-554, https://doi.org/10.1016/j.promfg.2017.07.148.

4. Bekas, D.G.; Hou, Y.; Liu, Y.; Panesar, A. 3D printing to enable multifunctionality in polymer-based composites: A review. Composites Part B: Engineering 2019, 175, https://doi.org/10.1016/j.compositesb.2019.107540.

5. Fu, K.; Yao, Y.; Dai, J.; Hu, L. Progress in 3D Printing of Carbon Materials for Energy-Related Applications. Advanced Materials 2017, 29, https://doi.org/10.1002/adma.201603486.

6. Tian, X.; Liu, T.; Yang, C.; Wang, Q.; Li, D. Interface and performance of 3D printed continuous carbon fiber reinforced PLA composites. Composites Part A: Applied Science and Manufacturing 2016, 88, 198205, https://doi.org/10.1016/j.compositesa.2016.05.032.

7. Rymansaib, Z.; Iravani, P.; Emslie, E.; Medvidović-Kosanović, M.; Sak-Bosnar, M.; Verdejo, R.; Marken, F. All-Polystyrene 3D-Printed Electrochemical Device with Embedded Carbon Nanofiber-GraphitePolystyrene Composite Conductor. Electroanalysis 2016, 28, 1517-1523, https://doi.org/10.1002/elan.201600017.

8. Wei, X.; Li, D.; Jiang, W.; Gu, Z.; Wang, X.; Zhang, Z.; Sun, Z. 3D Printable Graphene Composite. Scientific Reports 2015, 5, https://doi.org/10.1038/srep11181.

9. Zhong, J.; Zhou, G.-X.; He, P.-G.; Yang, Z.-H.; Jia, D.-C. 3D printing strong and conductive geo-polymer nanocomposite structures modified by graphene oxide. Carbon 2017, 117, 421-426, https://doi.org/10.1016/j.carbon.2017.02.102.

10. Hashemi Sanatgar, R.; Campagne, C.; Nierstrasz, V. Investigation of the adhesion properties of direct 3D printing of polymers and nanocomposites on textiles: Effect of FDM printing process parameters. Applied Surface Science 2017, 403, 551-563, https://doi.org/10.1016/j.apsusc.2017.01.112.

11. Zang, X.; Jiang, M.; Zhou, Z.; Gou, J.; Hui, D. 3D printing of polymer matrix composites: A review and prospective. Composites Part B: Engineering 2017, 110, 442-458, https://doi.org/10.1016/j.compositesb.2016.11.034.

12. Gnanasekaran, K.; Heijmans, T.; van Bennekom, S.; Woldhuis, H.; Wijnia, S.; de With, G.; Friedrich, H. 3D printing of CNT- and graphene-based conductive polymer nanocomposites by fused deposition modeling. Applied Materials Today 2017, 9, 21-28, https://doi.org/10.1016/j.apmt.2017.04.003.

13. Postiglione, G.; Natale, G.; Griffini, G.; Levi, M.; Turri, S. Conductive 3D microstructures by direct 3D printing of polymer/carbon nanotube nanocomposites via liquid deposition modeling. Composites Part A: Applied Science and Manufacturing 2015, 76, 110-114, https://doi.org/10.1016/j.compositesa.2015.05.014.

14. Zhang, D.; Chi, B.; Li, B.; Gao, Z.; Du, Y.; Guo, J.; Wei, J. Fabrication of highly conductive graphene flexible circuits by 3D printing. Synthetic Metals 2016, 217, 79-86, https://doi.org/10.1016/j.synthmet.2016.03.014. 
15. Manganiello, C.; Naso, D.; Cupertino, F.; Fiume, O.; Percoco, G. Investigating the Potential of CommercialGrade Carbon Black-Filled TPU for the 3D Printing of Compressive Sensors. Micromachines 2019, 10, https://doi.org/doi:10.3390/mi10010046.

16. Gotoh, K.; Kinumoto, T.; Fujii, E.; et al. Exfoliated graphene sheets decorated with metal/metal oxide nanoparticles: Simple preparation from cation exchanged graphite oxide. Carbon 2011, 49, 1118-1125, https://doi.org/10.1016/j.carbon.2010.11.017.

17. Jiang, L.; Gao, L. Fabrication and Characterization of Carbon Nanotube-Titanium Nitride Composites with Enhanced Electrical and Electrochemical Properties. Journal of the American Ceramic Society 2006, 89, 156-161, https://doi.org/10.1111/j.1551-2916.2005.00687.x.

18. Michalska-Domańska, M.; Jóźwik, P.; Jankiewicz, B.J.; Bartosewicz, B.; Siemiaszko, D.; Stępniowski, W.J.; Bojar, Z. Study of Cyclic Ni3Al Catalyst Pretreatment Process for Uniform Carbon Nanotubes Formation and Improved Hydrogen Yield in Methanol Decomposition. Materials Today: Proceedings 2016, 3, S171S177, https://doi.org/10.1016/j.matpr.2016.02.029.

19. Mazzanti, V.; Malagutti, L.; Mollica, F. FDM 3D Printing of Polymers Containing Natural Fillers: A Review of their Mechanical Properties. Polymers 2019, 11, https://doi.org/doi:10.3390/polym11071094.

20. Pop, M.A.; Croitoru, C.; Bedő, T.; Geamăn, V.; Radomir, I.; Cos, n.ă.M.; Zaharia, S.M.; Chicos, L.A.; Milos, a.I. Structural changes during 3D printing of bioderived and synthetic thermoplastic materials. Journal of Applied Polymer Science 2019, 136, https://doi.org/10.1002/app.47382.

21. Lei, Z.; Chen, Z.; Zhou, Y.; et al. Novel electrically conductive composite filaments based on Ag/saturated polyester/polyvinyl butyral for 3D-printing circuits. Composites Science and Technology 2019, 180, 44-50, https://doi.org/10.1016/j.compscitech.2019.05.003.

22. Nebojsa, I.J.; Pratik, D.D. Characterization of 3D-printed capacitors created by fused filament fabrication using electrically-conductive filament. Procedia Manufacturing, 2019, 38, 33-41, https://doi.org/10.1016/j.promfg.2020.01.005.

23. Tan, J.C.; Low, H.Y. Embedded electrical tracks in 3D printed objects by fused filament fabrication of highly conductive composites. Additive Manufacturing, 2018, 23, 294-302, https://doi.org/10.1016/j.addma.2018.06.009.

24. Ebrahimi, N.D; Ju, Y.S. Thermal conductivity of sintered copper samples prepared using 3D printingcompatible polymer composite filaments. Additive Manufacturing, 2018, 24, 479-485, https://doi.org/10.1016/j.addma.2018.10.025.

25. Wang, J.; Mubarak, S.; Dhamodharam, D.; et al. Fabrication of thermoplastic functionally gradient composite parts with anisotropic thermal conductive properties based on multicomponent fused deposition modeling 3D printing. Composite Communications, 2020, 19, 142-146, https://doi.org/10.1016/j.coco.2020.03.012. 